\title{
Bibliotecas comunitarias en Brasil: dónde están, por qué y cómo fueron creadas
}

\author{
Bibliotecas comunitárias no Brasil: donde estão, porque e como foram criadas (1)
}

Community libraries in Brasil: where they are, why and how they were created

Elisa Campos Machado (1), Waldomiro Vergueiro (2)

(1) Departamento de Estudos e Processos Biblioteconômicos - Universidad Federal do Estado do Rio de Janeiro, Av. Pasteur, 458, Urca, Río de Janeiro, Brasil, emachado2005@gmail.com (2) Escola de Comunicações e Artes - Universidade de São Paulo (ECAUSP), Av. Prof. Lúcio Martins Rodrigues, 443, São Paulo, SP, Brasil, 05508-900, wdcsverg@usp.br

\begin{abstract}
Resumen
Resultado de investigación cualitativa sobre la creación de bibliotecas comunitarias en Brasil, con un análisis descriptivo de los locales donde se encuentran, las motivaciones para su creación y las formas como eses procesos son iniciados. Destaca las diferencias entre las iniciativas creadas por agentes individuales y colectivos, internos y externos a la comunidad. Defiende que las particularidades y las grandes diferencias entre las experiencias son también resultado de las distinciones regionales y culturales que caracterizan al país. Considera esas bibliotecas espacios de negociación, de apropiación y de rescate de la identidad para las comunidades. La lectura, y no la organización y tratamiento de la información, es la actividad que permea todo el proceso.
\end{abstract}

Palabras clave: Bibliotecas comunitarias. Bibliotecas públicas.

\section{Introdução}

O Brasil enfrenta até hoje o desafio de dar acesso e potencializar o uso da leitura e da informação a todos os seus cidadãos. Apesar dos esforços governamentais no sentido de criar um Plano Nacional de Cultura, as políticas públicas para bibliotecas ainda não conseguiram avançar de maneira impactante.

Segundo o Anuário de Estatísticas Culturais de 2009, pelo menos $10 \%$ dos municípios brasileiros não possuem biblioteca pública (CULTURA, 2009). Silva (2010) faz um alerta para dois fatos que têm gerado uma inversão de valores na sociedade em relação às bibliotecas públicas: a vergonhosa situação em que se encontram as bibliotecas públicas no Brasil e a forma como a mídia divulga e enaltece as bibliotecas comunitárias.

São muitas as diferenças entre as bibliotecas públicas e as comunitárias. A pública é entendida como a que possui vinculação direta com o poder público, criada e mantida por secretarias de cultura e educação, conta com a atuação de

\begin{abstract}
It is the result of a qualitative research on the establishment of community libraries in Brazil, with a descriptive analysis emphasizing where they are, the motivation for their creation and the means for trigging these processes. It highlights the differences between enterprises created by individual and collective agents, both internal as external to the community. It defends that the specificities and the great differences among the experiments are due to the country's regional and cultural distinctions. It considers those libraries as spaces for negotiation, appropriation and identity recuperation by the communities. The reading, and not information organization and processing, is the activity which permeates all the process.
\end{abstract}

Keywords: Community libraries. Public libraries.

funcionários públicos. A comunitária é considerada um empreendimento social, sem vínculo direto com instituições governamentais, liderada por um grupo organizado de pessoas de uma comunidade. Ambas têm por objetivo dar acesso à informação e à leitura, sendo que a primeira, oficialmente, conta com recursos financeiros públicos e com profissional especializado, o bibliotecário, que além de dar acesso possui formação para garantir e potencializar o uso da informação e da leitura.

A partir dessa realidade, buscou-se analisar o contexto que envolve as bibliotecas comunitárias no país, suas características e perfil de seus idealizadores. Para tanto, baseado em metodologias qualitativas e objetivos exploratórios, foi realizado, no período de 2006 a 2008, um levantamento que resultou na identificação de 350 experiências, cujos resultados analíticos são apresentados a seguir. 


\section{Onde se encontram as bibliotecas comunitárias}

Com raras exceções, a grande maioria das bibliotecas identificadas está em áreas de exclusão, localidades carentes, de difícil acesso, seja por distância ou por relação de vulnerabilidade. Em geral, as localidades, regiões rurais ou periferias dos grandes centros urbanos, não possuem equipamentos culturais

Também existem bibliotecas comunitárias em regiões nobres de grandes centros urbanos, mas sediadas em zonas "excluídas". Nesses casos, as regiões são ricas em equipamentos culturais, porém estes são orientados para atender um público de poder aquisitivo maior.

\section{Os motivos para sua criação}

Das 350 bibliotecas levantadas, 29 foram selecionadas para compor o universo da pesquisa (Anexo A). A partir dele, foi possível identificar o motivo principal para a criação desses espaços: a dificuldade de acesso ao livro e à leitura, ou seja, a carência de espaços públicos para esse fim - bibliotecas públicas e escolares. Apesar de o motivo desencadeador ser o mesmo, a forma como surge cada uma das bibliotecas e o seu estabelecimento na comunidade seguem caminhos diferentes.

Entre as razões para criação de bibliotecas comunitárias está o interesse de pessoas ou grupos em interferir nos rumos da sociedade, propondo e se dedicando à organização de equipamentos culturais que permitam atingir esse objetivo. Sob esse ponto de vista, as iniciativas identificadas na pesquisa podem ser divididas entre as que surgiram a partir de iniciativas individuais e as que provieram de iniciativas coletivas internas ou externas à comunidade.

\subsection{Projetos criados a partir de iniciativas} individuais

Varias experiências de criação de bibliotecas comunitárias surgiram do desejo de uma pessoa abrir sua casa ou biblioteca particular para a comunidade. De uma maneira voluntária, seguindo princípios filantrópicos, o agente organiza um espaço visando compartilhar seu conhecimento e seu prazer pela leitura e, assim, contribuir para melhorar os níveis de leitura, educação e cultura da sua comunidade. São indivíduos com as mais diversas formações, muitos deles com pouca ou nenhuma escolaridade.

Das 29 experiências, 7 se enquadram nessa condição.

\begin{tabular}{ll}
\hline \multicolumn{1}{c}{ Biblioteca } & \multicolumn{1}{c}{ Criador } \\
\hline Biblioteca Solidária (SP) & Bibliotecário \\
\hline Biblioteca dos Garis (SP) & Ex-seminarista \\
\hline $\begin{array}{l}\text { Biblioteca Comunitária T- } \\
\text { Bone (DF) }\end{array}$ & Açougueiro \\
\hline $\begin{array}{l}\text { Biblioteca Comunitária } \\
\text { Tobias Barreto (RJ) }\end{array}$ & Pedreiro \\
\hline Biblioteca Comunitária & Catador de lixo \\
Prestes Maia (SP) & \\
\hline $\begin{array}{l}\text { Biblioteca Comunitária Maria } \\
\text { das Neves Prado (BA) }\end{array}$ & Professor \\
\hline $\begin{array}{l}\text { Biblioteca Comunitária de } \\
\text { Poços de Caldas (MG) }\end{array}$ & Fazendeiro \\
\hline
\end{tabular}

Quadro I. Iniciativa individual

A Biblioteca Solidária localizada no Distrito de São Francisco Xavier, em São José dos Campos, foi criada por um bibliotecário que, ao retornar a sua cidade natal, propôs à Secretaria de Cultura do município a criação de uma biblioteca pública. Ao ter sua proposta recusada, decidiu montar uma biblioteca em sua casa.

A Biblioteca dos Garis, na cidade de São Paulo, foi idealizada por um ex-seminarista que teve uma infância pobre, só tendo acesso à leitura porque seus pais, embora analfabetos, não deixavam de comprar livros dos mascates que batiam à sua porta.

A Biblioteca Comunitária T-Bone, de Brasília, foi inicialmente situada em um açougue, por iniciativa do proprietário, o que perdurou até que a vigilância sanitária fechou o açougue por causa da "convivência" indevida entre livros e carnes. A partir desse incidente, a biblioteca foi transferida para uma casa próxima. Para garantir a sustentabilidade do projeto foi criada a ONG (2) T-Bone, para viabilizar apoios e parcerias com instituições públicas e privadas.

Em alguns desses casos, o agente individual muda sua posição no grupo e na sociedade a partir da iniciativa e a biblioteca passa a ser o seu passaporte para integrar um novo grupo ou mundo. Estão em jogo espaços sociais e formas de poder. Quando isto se torna o motivo de existência da biblioteca, fecham-se as portas para a participação da comunidade e a biblioteca passa a ter um "dono". Em relação a isso, com base no pensamento de Bourdieu (2005), podemos inferir que a biblioteca é vista por esse agente individual como um meio de ampliar seu capital cultural e social, de maneira a torná-lo diferente na estrutura do campo de forças do qual faz parte.

Tal aconteceu com a Biblioteca Comunitária Tobias Barreto, na cidade do Rio de Janeiro. Seu criador, um pedreiro, transformou sua casa 
em um depósito de livros e, com a mídia a seu favor, conseguiu projeção nacional (Arruda, 2004; Bndes, 2005; Vianna, 2006). Os que procuram sua casa passam a depender de sua presença e memória para encontrar um livro no emaranhado de pilhas que se espalham pelos diversos cômodos.

A Biblioteca Comunitária Prestes Maia, na cidade de São Paulo, idealizada por um casal de catadores de lixo, tem história semelhante. Ao recolher livros do lixo, o casal os alocou em um espaço no porão do prédio invadido pelo Movimento dos Sem Tetos do Centro (MSTC) e ofereceu esse acervo para consulta e empréstimo da comunidade moradora. Eram, à época, aproximadamente 2.000 pessoas organizadas em uma complexa relação de sociabilidade, cheia de contradições, que mobilizava e impulsionava o grupo no sentido de desenvolver uma serie de práticas coletivas. Nesse ambiente, o casal montou a biblioteca e obteve projeção na mídia (Balazina, 2006).

A biblioteca era um "bem patrimonial" do casal e não do grupo que constituía a ocupação. Era um espaço aberto à coletividade, mas não da coletividade. Entretanto, existem casos em que a biblioteca é criada por uma pessoa e esta se coloca como membro da comunidade e, por meio de ações pedagógicas, vai construindo estratégias para que o projeto, que começou como ação individual, se transforme em ação coletiva. Essas pessoas conhecem as dificuldades locais e acreditam que, sozinha, a comunidade não vai criar uma biblioteca. Tal se passou na Biblioteca Comunitária Maria das Neves Prado, localizada no município de Nova Soure e na Biblioteca Comunitária de Poços de Caldas.

\subsection{Projetos criados a partir de iniciativas coletivas}

Existem também experiências em que a motivação para a criação dos projetos parte de agentes coletivos internos e/ou externos à comunidade.

A maioria dos agentes coletivos internos à comunidade é representada por jovens organizados em movimentos sociais locais. Sete experiências com estas características fizeram parte do universo pesquisado.

O perfil da primeira biblioteca desse grupo se diferencia por ter sido criada para apoiar o ensino e a pesquisa da Escola, do Movimento dos Sem Terra (MST). Tem características de uma biblioteca universitária que atende também a comunidade local.

\begin{tabular}{|c|c|}
\hline Biblioteca & Criador \\
\hline $\begin{array}{l}\text { Biblioteca Confraria dos } \\
\text { Parceiros de Guararema } \\
\text { (SP) }\end{array}$ & $\begin{array}{lll}\text { Movimento } & \text { dos } & \text { Sem } \\
\text { Terra (MST) } & & \end{array}$ \\
\hline $\begin{array}{l}\text { Biblioteca Comunitária } \\
\text { Paulo Freire (RJ) }\end{array}$ & $\begin{array}{l}\text { Grupo de moradores da } \\
\text { Maré, no Rio de Janeiro. }\end{array}$ \\
\hline $\begin{array}{l}\text { Biblioteca Comunitária } \\
\text { Livro-Pra-Quê-Te-Quero } \\
\text { (SP) }\end{array}$ & $\begin{array}{l}\text { Posse Poder e } \\
\text { Revolução, movimento } \\
\text { juvenil da Vila Livieiro, } \\
\text { em São Paulo }\end{array}$ \\
\hline $\begin{array}{l}\text { Biblioteca Comunitária } \\
\text { Solano Trindade (SP) }\end{array}$ & $\begin{array}{l}\text { Grupo de jovens do } \\
\text { Núcleo Cultural Força } \\
\text { Ativa, em Cidade } \\
\text { Tiradentes, São Paulo } \\
\end{array}$ \\
\hline $\begin{array}{l}\text { Biblioteca Comunitária } \\
\text { Zumaluma (SP) }\end{array}$ & $\begin{array}{l}\text { Grupo de jovens } \\
\text { moradores da favela } \\
\text { Inferninho, em Embu das } \\
\text { Artes. }\end{array}$ \\
\hline $\begin{array}{l}\text { Biblioteca Comunitária de } \\
\text { Heliópolis (SP) }\end{array}$ & $\begin{array}{l}\text { Projeto Identidade } \\
\text { Cultural de Heliópolis, em } \\
\text { São Paulo. }\end{array}$ \\
\hline $\begin{array}{l}\text { Biblioteca Comunitária } \\
\text { Prof. Waldir de Souza Lima } \\
\text { (SP) }\end{array}$ & $\begin{array}{l}\text { Grupo de jovens } \\
\text { moradores de Itu. }\end{array}$ \\
\hline
\end{tabular}

Quadro II. Iniciativa coletiva interna à comunidade)

As outras 6 experiências surgiram do desejo da comunidade. Em um dos casos, estimulada e apoiada por agentes externos, e, nos outros, criadas de maneira espontânea, a partir da necessidade identificada pelo grupo.

A Biblioteca Comunitária de Heliópolis é bastante peculiar. Sua criação teve o estímulo e apoio de agentes externos, como parte de um plano de ação denominado "Programa de Identidade Cultural de Heliópolis", concebido pelo arquiteto Ruy Ohtake (2006) em conjunto com a comunidade local. A partir de várias reuniões e discussões com moradores, jovens da comunidade e especialistas, o grupo elegeu a biblioteca como prioridade da comunidade.

A Biblioteca Comunitária Paulo Freire, da cidade do Rio de Janeiro, surgiu a partir da iniciativa de um grupo de moradores que tinham em comum a formação universitária e a trajetória de militância em movimentos sociais. Com o objetivo de enfrentar e superar as condições de pobreza e exclusão do bairro, definiu como uma de suas primeiras intervenções a criação do PréVestibular Comunitários Maré (CPV- Maré). Foi nesse contexto que a idéia de criar um espaço de leitura e troca de livros se consolidou. Ao longo do tempo, alguns desses jovens entraram em cursos de Biblioteconomia e Arquivologia (3) e se envolveram em um projeto de extensão para apoiar a organização do acervo e manutenção dos serviços da biblioteca.

$\mathrm{Na}$ mesma linha encontra-se a Biblioteca Comunitária Livro-Pra-Quê-Te-Quero, que surgiu dentro do movimento Posse (4) Poder e Revo- 
lução, na cidade de São Paulo, formada, na época, por 40 jovens que declararam, na sua carta de princípios, que um de seus objetivos era criar uma biblioteca comunitária. Durante suas intervenções culturais, arrecadavam-se livros para suprir a necessidade de estudos daqueles que estavam se preparando para o vestibular.

No início, não se tinha espaço onde abrigar aquele acervo e somente em 2004 inauguraram a Maloca Espaço Cultural e ali abrigaram a Biblioteca Comunitária, espaço conquistado por meio da parceria com uma ONG e uma instituição pública.

A Biblioteca Comunitária Solano Trindade, na cidade de São Paulo, também surgiu como apoio ao estudo e à pesquisa de jovens ligados a um movimento do Hip Hop, o Núcleo Cultural Força Ativa. Em 1994, percebendo a necessidade de estimular a leitura e o acesso à informação para melhorar o processo de criação dos jovens envolvidos nas diversas manifestações, um dos integrantes fez a música intitulada "Vamos ler um livro". No entanto, ele e seus companheiros perceberam que era difícil incentivar a leitura sem acesso a documentos textuais. Foi assim que se iniciou a mobilização para a criação da biblioteca comunitária como forma de denuncia da ausência de bibliotecas públicas no bairro. Somente em 2001 o grupo conseguiu inaugurar a Biblioteca Comunitária.

Já os criadores da Biblioteca Zumaluna, no município de Embu das Artes, declaram que tomaram essa iniciativa por ser o único caminho em oposição ao tráfico de drogas. Moradores da favela, jovens, homens, negros, desempregados e sem perspectivas, resolveram ocupar uma casa abandonada, utilizada à época como espaço para o consumo e trafico de drogas e prostituição, e ali situar a biblioteca comunitária.

A idéia de criar a Biblioteca Comunitária Prof. Waldir de Souza Lima surgiu de um grupo de "agitadores culturais" de Itu, jovens e adultos que inconformados com a falta de opções culturais na região. A única biblioteca pública da cidade de Itu, com cerca de 150 mil habitantes, funciona de $2^{\mathrm{a}}$. a $6^{\mathrm{a}}$. feira, das $8 \mathrm{~h}$ às $17 \mathrm{~h}$. $\mathrm{O}$ objetivo do grupo era ter uma alternativa de horário aos finais de semana e no período noturno, bem como um acervo mais diversificado.

No que se refere aos agentes coletivos externos, verificou-se a forte presença de ONGs provenientes das mais variadas áreas, vinculadas ou não a instituições privadas. São institutos e fundações vinculados a empresas, a instituições educacionais, assim como cooperativas, associações de bairros, escolas de samba e entidades religiosas, ou, ainda, organizações criadas especificamente para esse fim.

Das 29 experiências analisadas, 15 se enquadram nessa condição.

\begin{tabular}{ll}
\hline Biblioteca & Criador \\
\hline $\begin{array}{l}\text { Biblioteca Comunitária } \\
\text { Emmanuel (RJ) }\end{array}$ & $\begin{array}{l}\text { Obra São João } \\
\text { Baptista }\end{array}$ \\
\hline $\begin{array}{l}\text { Biblioteca Comunitária } \\
\text { Cultura Jovem (SP) }\end{array}$ & $\begin{array}{l}\text { Fundação Fé e Alegria } \\
\text { do Brasil e Sociedade } \\
\text { Santo Mártires }\end{array}$ \\
\hline $\begin{array}{l}\text { Biblioteca Comunitária } \\
\text { Paulo Coelho (RJ) }\end{array}$ & Solar Meninos de Luz \\
\hline $\begin{array}{l}\text { Bibliotecas Vaga Lume - } \\
\text { 6 experiências (AP, MA, } \\
\text { PA e RR) }\end{array}$ & $\begin{array}{l}\text { Associação Vaga } \\
\text { Lume }\end{array}$ \\
\hline $\begin{array}{l}\text { Bibliotecas Comunitárias } \\
\text { Ler é Preciso - 4 } \\
\text { experiências (SP e RJ) }\end{array}$ & Instituto Ecofuturo \\
\hline $\begin{array}{l}\text { Biblioteca Comunitária } \\
\text { do Projeto Casulo (SP) }\end{array}$ & Instituto de Cidadania \\
\hline $\begin{array}{l}\text { Biblioteca Comunitária } \\
\text { do Espaço Criança }\end{array}$ & TV Globo e Viva Rio \\
Esperança (RJ) & \\
\hline
\end{tabular}

Quadro III. Iniciativa coletiva externa à comunidade. Fonte: Os autores (2010).

As três primeiras experiências do Quadro III foram criadas por organizações religiosas. A Biblioteca Comunitária Paulo Coelho, apesar do nome, caracteriza-se como uma biblioteca escolar, pois atende a Creche-Escola Meninos de Luz. Já a Biblioteca Comunitária Emmanuel e a Biblioteca Comunitária Cultura Jovem, situadas respectivamente, na cidade do Rio de Janeiro e de São Paulo, por sua forma de gestão, que estimula o envolvimento da comunidade local, aproximam-se mais do conceito de biblioteca comunitária aqui proposto.

A Associação Vaga Lume é criada com o objetivo de ampliar o acesso ao livro e à leitura em comunidades rurais da região amazônica.

$\mathrm{Na}$ Amazônia, em sua maioria, o espaço que serve de apoio para o projeto é a escola local, pois são localidades longínquas, de difícil acesso, nas quais a praça, a igreja, a escola e o posto de saúde são os pontos centrais. Nesses casos, apesar de se denominarem bibliotecas comunitárias na tipologia biblioteconômica, a maioria das Bibliotecas Vaga Lume se caracteriza como biblioteca escolar. É o caso das bibliotecas Vaga Lume de Vista Alegre, em Caracaraí, e de Boca da Mata, em Pacaraima, ambas no Estado de Roraima, assim como da comunidade Corre Água de Piririm, em Macapá, no Estado do Amapá. 
Entretanto, é importante ressaltar que, nos três casos citados, apesar da biblioteca estar sediada numa escola, a comunidade se apropriou do espaço. O fato dessas bibliotecas estarem sediadas na escola é apenas contingencial. Nas comunidades, o princípio de participação faz parte da cultura local, visto que elas preservam os hábitos e costumes indígenas, que valorizam o processo democrático de tomada de decisão.

Cabe esclarecer que não é regra que as bibliotecas criadas pela Expedição Vaga Lume fiquem sediadas na escola. Essa decisão é da comunidade: "cada intervenção é planejada e adaptada às condições da realidade local" (Associação Vaga Lume, 2005). Exemplo disso é a Biblioteca Vaga Lume da Comunidade Santa Tereza, de Mirinzal, no Estado do Maranhão. O projeto, sob a liderança de um morador local, teve seu início num espaço cedido pela escola. Porém, ao longo do tempo, a comunidade Quilombola de Santa Tereza decidiu transferir o acervo para a sala da casa de um dos moradores locais.

A Biblioteca Vaga Lume da Comunidade Bengui, na periferia de Belém, também conseguiu criar o seu próprio espaço na casa de uma mediadora de leitura formada pelo programa. O acervo, que inicialmente só podia ser utilizado pelos alunos da escola local, passou a ser disponibilizado para todos os moradores da comunidade.

O Projeto Ler é Preciso, por sua vez, uma ação do Instituto Ecofuturo, tem por objetivo a criação de bibliotecas comunitárias. Até dezembro de 2007, 70 bibliotecas foram implantadas pelo programa, sendo que quatro delas fizeram parte da pesquisa, a Biblioteca da Coopamare, a Biblioteca Prof. Diuner Mello, a Biblioteca de Magé e a Biblioteca de Copacabana.

$\mathrm{Na}$ Biblioteca da Coopamare, na cidade de São Paulo, o Instituto Ecofuturo agiu como estimulador e apoiador para uma iniciativa que fazia parte do desejo da comunidade de catadores de lixo e o grupo, pela experiência de atuação na cooperativa, incorporou os princípios de participação na gestão da biblioteca.

Tanto a Biblioteca Prof. Diuner Mello, de Parati (RJ), como a Biblioteca de Magé (RJ), foram incorporadas pela escola local e assumiram a função de biblioteca escolar.

Já a Biblioteca de Copacabana é, na realidade, uma biblioteca pública. Por meio de uma parceria junto à Secretaria Municipal das Culturas do Rio de Janeiro o Instituto Ecofuturo viabilizou a melhoria de um órgão público, doando livros, mobiliário e oferecendo cursos de formação para a equipe. Apesar de ter sido divulgado e constar da relação de bibliotecas comunitárias criadas pelo Instituto Ecofuturo, trata-se de apoio a uma biblioteca pública já existente.

Outra iniciativa coletiva que colaborou para a criação de uma biblioteca comunitária é o Projeto Casulo vinculado ao Instituto de Cidadania Empresarial (ICE), que tem por objetivo estimular o desenvolvimento comunitário dos moradores das favelas do Real Parque e Jardim Panorama, na cidade de São Paulo. Com mais de 4.000 pessoas, essas favelas ficam localizadas no Morumbi, bairro com maior renda média por habitante, da cidade de São Paulo. A ausência de políticas públicas para atuar junto a esse grupo levou a sociedade civil, por meio do ICE, a se organizar e criar meios para agir no lugar do Estado.

O ICE a partir de um diagnóstico local, constatou que $16 \%$ daquela população era analfabeta e que somente $9,5 \%$ buscavam informação na leitura e por essa razão elegeu o acesso ao livro e à leitura como um dos focos de suas ações. $O$ primeiro passo foi a formação de jovens mediadores de leitura e, na seqüência, a discussão de como deveria ser a biblioteca. No entanto, como esses jovens poderiam responder essa questão, se suas vivências de leitura na escola e de biblioteca eram tão sofridas ou quase inexistentes? Assim, os organizadores do projeto decidiram iniciar uma pesquisa sobre o assunto e visitar bibliotecas públicas e universitárias para criar seus próprios parâmetros.

As três organizações acima citadas têm a preocupação de eleger membros da comunidade para atuar no processo de implantação e manutenção das bibliotecas. Para isso, prevêem a formação desses agentes, fazendo com que membros da comunidade sejam os atores do processo.

Já a biblioteca do Espaço Criança Esperança, na cidade do Rio de Janeiro, administrada pela TV Globo, com a parceria da ONG Viva Rio, se diferencia nesse contexto. Tendo sido criada para complementar uma gama de atividades educacionais e culturais oferecida aos moradores das favelas do Cantagalo, Pavão e Pavãozinho, conta com funcionários contratados pela instituição, o que resulta num baixo nível de envolvimento da comunidade.

\section{Conclusão}

Esta pesquisa pautou seus resultados na ótica dos aspectos humanos, dos movimentos e dinâmicas locais. Sob esse ponto de vista, constata-se que as pessoas envolvidas nesses projetos são lideranças sensíveis, acostumadas a passar 
por situações de extrema necessidade, que, no entanto, conseguem fazer a diferença num mundo tão adverso. De forma ativa e contrastante, enfrentam o cotidiano da exclusão de acordo com suas histórias coletivas, trajetórias individuais e características socioculturais e geográficas das localidades em que se encontram.

A diversidade cultural brasileira ficou evidenciada nas experiências analisadas, assim como os campos de tensão que afloram nesses projetos. Existem grandes diferenças entre as experiências, mas pode-se identificar a importância que as bibliotecas comunitárias têm nesses espaços o que é resultado da crença que esses grupos têm na sua comunidade.

A biblioteca comunitária, no Brasil, pode ser vista como um espaço de negociação, de apropriação e de resgate da identidade. E a atividade que permeia todo esse processo é a leitura individual, coletiva ou mediada. Sobre esse aspecto, cabe lembrar que temos um déficit imenso de leitura e de leitores no país. Se o ensino formal não dá conta desta demanda, por meio das escolas e de suas bibliotecas, e se não existem bibliotecas públicas suficientes para atender a necessidade de auto-formação da população, a criação da biblioteca comunitária passa a ser o caminho natural encontrado pelas comunidades locais para apoiá-la, entendendo-a como uma das mais importantes ferramentas de emancipação do homem.

No entanto, é imprescindível afirmar que as bibliotecas comunitárias não substituem as bibliotecas públicas. Apesar de algumas delas apresentarem um bom desempenho no que se refere ao estímulo à leitura, elas não conseguem chegar a um nível de especialização suficiente para trabalhar efetivamente com o acesso à informação. Esta é ainda uma meta a ser atingida.

\section{Notas}

(1) Tese defendida em dezembro de 2008, no Programa de Pós-Graduação em Ciência da Informação, Área de Concentração Cultura e Informação, Linha de Pesquisa: Acesso à Informação, da Escola de Comunicações e Artes da Universidade de São Paulo, como exigência parcial para obtenção do Título de Doutor em Ciência da Informação sob a orientação do Prof. Dr. Waldomiro de Castro Santos Vergueiro.

(2) Organização não governamental (ONG).

(3) Universidade Federal do Estado do Rio de Janeiro (UNIRIO).

(4) Posse é o movimento que reúne vários grupos de rappers, grafiteiros, MCs (mestre de cerimônia) músicos e simpatizantes do Hip Hop.

\section{Referencias}

Arruda, Antonio. Para construir leitores. Folha Online, São Paulo, 29 set. 2004. http://www1.folha.uol.com.br /folha/sinapse/ult1063u931.shtml (2007-08-27).

Balazina, Afra. Sem-teto faz biblioteca em prédio invadido. Folha de S. Paulo, São Paulo, 1 fev. 2006. Cotidiano, Literatura subterrânea, p. C2

Biblioteca Nacional (Brasil). Sistema Nacional de Bibliotecas Públicas. Relatório anual. [2006?]. http://catalogos. bn.br/snbp/. (2007-03-02).

Bourdieu, Pierre. Razões práticas: sobre a teoria da ação. 7. ed. Campinas: Papirus, 2005.

Brasil. Ministério da Cultura. Por que aprovar o Plano Nacional de Cultura: conceitos, participação e expectativas. Brasília: MinC, 2009.

BNDES paga parceria de Niemeyer e pedreiro. Folha de $\mathrm{S}$. Paulo, São Paulo, 28 out. 2005. Cotidiano, Literatura concretista, p. C5.

Cultura em números: anuário de estatísticas culturais 2009. Brasília: Minc, 2009.

Machado, Elisa Campos. Bibliotecas comunitárias como prática social no Brasil. 2008. Escola de Comunicação e Artes, Universidade de São Paulo. Tese (doutorado).

Machado, Elisa Campos. Uma discussão acerca do conceito de Biblioteca Comunitária. Revista Digital de Biblioteconomia e Ciência da Informação, Campinas. 7:1 (jul./dez. 2009) 80-94

Ohtake, Ruy. Heliópolis: projeto de identidade cultural em conjunto com a comunidade. São Paulo, 2006.

Prado, Geraldo Moreira. Bibliotecas comunitárias no semiárido brasileiro: miniterritório de memória da inclusão sociocultural. 2006. Projeto de pesquisa aprovado pelo CNPq. Edital MCT/CNPq 50/2006 - Ciências Humanas, Sociais e Sociais Aplicadas, 2007. Não publicado.

Silva, Ezequiel Theodoro da. O bibliotecário e a mediação. // Revista Educação. Edição 153 (jan. 2010) http:// revistaeducacao.uol.com.br/revista.asp. (2010-06-24).

Vianna, Luiz Fernando. Pedreiro cria um dicionário de ilustres desconhecidos. // Folha de S. Paulo. São Paulo. 3 (dez. 2006). Cotidiano, Educação, p. C3.

Recibido: 23-04-2010. Revisado: 08-07-010.

Aceptado: 08-07-2110. 
Anexo A: Universo da pesquisa - 29 experiências analisadas

\begin{tabular}{|c|c|c|c|c|}
\hline & Biblioteca & $U F$ & Cidade & Bairro/Região \\
\hline 1 & BVL de Macapá & $\mathrm{AP}$ & Macapá & Corre Água do Piririm \\
\hline 2 & BC Maria das Neves Prado & $\mathrm{BA}$ & Nova Soure & São José do Paiaiá \\
\hline 3 & BC T Bone & DF & Brasília & Asa Norte \\
\hline 4 & BVL da Comunidade Santa Tereza & MA & Mirinzal & Quilombo Santa Tereza \\
\hline 5 & BC de Poços de Caldas & MG & Poços de Caldas & Zona rural \\
\hline 6 & BVL da Comunidade Bengui & PA & Belém & Benguí \\
\hline 7 & BC Ler é Preciso de Magé & RJ & Magé & Zona rural \\
\hline 8 & BC Ler é Preciso Diuner Mello & RJ & Paraty & Taquari, zona rural \\
\hline 9 & BC Emmanuel & RJ & Rio de Janeiro & Magalhães Bastos \\
\hline 10 & BC do Espaço Criança Esperança & RJ & Rio de Janeiro & $\begin{array}{l}\text { Ipanema (Morro do } \\
\text { Cantagalo) }\end{array}$ \\
\hline 11 & BC Ler é Preciso de Copacabana & RJ & Rio de Janeiro & Copacabana \\
\hline 12 & BC Paulo Coelho & RJ & Rio de Janeiro & $\begin{array}{l}\text { Copacabana (Morro do } \\
\text { Pavão e Pavãozinho) }\end{array}$ \\
\hline 13 & BC Paulo Freire & RJ & Rio de Janeiro & Maré (Morro do Timbaú) \\
\hline 14 & BC Tobias Barreto & RJ & Rio de Janeiro & Penha \\
\hline 15 & BVL da Comunidade de Caracaraí & $\mathrm{RR}$ & Caracaraí & Vista Alegre \\
\hline 16 & BVL da Comunidade Boca da Mata & $\mathrm{RR}$ & Pacaraima & Boca da Mata \\
\hline 17 & BVL da Comunidade Santa Rosa & $\mathrm{RR}$ & Pacaraima & Santa Rosa \\
\hline 18 & BC Zumaluma & $\mathrm{SP}$ & Embu das Artes & Favela do Inferninho \\
\hline 19 & $\begin{array}{l}\text { Biblioteca Confraria dos Parceiros de } \\
\text { Guararema }\end{array}$ & $\mathrm{SP}$ & Guararema & Zona rural \\
\hline 20 & BC Prof. Waldir de Souza Lima & $\mathrm{SP}$ & Itu & Centro \\
\hline 21 & Biblioteca Solidária & $\mathrm{SP}$ & $\begin{array}{l}\text { São José dos } \\
\text { Campos }\end{array}$ & $\begin{array}{l}\text { Distrito de São Francisco } \\
\text { Xavier }\end{array}$ \\
\hline 22 & BC Casulo & $\mathrm{SP}$ & São Paulo & Parque Real \\
\hline 23 & BC Cultura Jovem & $\mathrm{SP}$ & São Paulo & Jardim Ângela \\
\hline 24 & BC dos Garis & $\mathrm{SP}$ & São Paulo & Centro \\
\hline 25 & BC de Heliópolis & $\mathrm{SP}$ & São Paulo & Favela de Heliópolis \\
\hline 26 & BC Ler é Preciso da Coopamare & SP & São Paulo & Pinheiros \\
\hline 27 & BC Livro-Pra-Quê-Te-Quero & $\mathrm{SP}$ & São Paulo & Parque Bristol/Vila Livieiro \\
\hline 28 & BC Prestes Maia & $\mathrm{SP}$ & São Paulo & Centro \\
\hline 29 & BC Solano Trindade & $\mathrm{SP}$ & São Paulo & Cidade Tiradentes \\
\hline
\end{tabular}

Quadro IV. Dados sobre as experiências pesquisas. Machado (2008) 
